\title{
Projeto social na área do esporte: acompanhamento de uma experiência extensionista
}

\section{Social project in the field of sport: monitoring of extension experience}

\section{Proyecto social en el área deportiva: seguimiento de una experiencia extensionista}

\author{
Andréa Rosana Fetzner ${ }^{1}$ \\ Arlindo Fernando Paiva de Carvalho Junior ${ }^{2}$ \\ Laís Conceição dos Santos ${ }^{1}$
}

DOI: http://dx.doi.org/10.20435/serie-estudos.v26i57.1531

\begin{abstract}
Resumo: Este trabalho, financiado pelo Ministério da Cidadania e pela Universidade Federal do Estado do Rio de Janeiro (UNIRIO), apresenta a experiência de pesquisa extensionista desenvolvida no acompanhamento do Projeto Cidadania em Ação, na área da Educação. O objetivo da pesquisa extensionista foi acompanhar, de forma participante, o oferecimento de esporte na faixa etária dos 6 aos 14 anos. A metodologia, de orientação qualitativa, envolveu observação participante, entrevistas e questionários. Para desenvolvimento do trabalho, foram acompanhados três núcleos do projeto, na cidade do Rio de Janeiro, que atendiam prioritariamente a faixa etária foco do estudo. Este artigo apresenta a avaliação dos participantes sobre o desenvolvimento das ações. O estudo indica aspectos em que o Projeto atende às proposições iniciais, em sua ação educativa e de integração entre os participantes, assim como limites, indicados pelos participantes, no que se refere principalmente aos materiais disponibilizados.
\end{abstract}

Palavras-chave: projeto social; pesquisa extensionista; satisfação dos participantes.

Abstract: This work, financed by the Ministry of Citizenship and by the Federal University of State of Rio de Janeiro (UNIRIO), presents the experience of extension research developed in the follow-up of the Cidadania em Ação Project, in the Education area. The purpose of the extension research was to follow, in a participatory way, the offer of sport in the age group from 6 to 14 years old. The methodology, of qualitative orientation, involved participant observation, interviews, and questionnaires. For the development of the work, three nuclei of the project were monitored, in the city of Rio de Janeiro, which primarily served the age range of the study. This paper presents

\footnotetext{
1 Universidade Federal do Estado do Rio de Janeiro (UNIRIO), Rio de Janeiro, Rio de Janeiro, Brasil.

2 Instituto Benjamin Constant, Rio de Janeiro, Rio de Janeiro, Brasil.
} 
the participants' evaluation of the development of actions. The study indicates aspects in which the Project meets the initial propositions, in its educational and integration action among the participants, as well as limits, indicated by the participants, regarding mainly the available materials.

Keywords: social project; extensionist research; participant satisfaction.

Resumen: Este trabajo, financiado por el Ministerio de Ciudadanía y la Universidad Federal del Estado de Rio de Janeiro (UNIRIO), presenta la experiencia de la investigación de extensión desarrollada en lo acompañamiento del Proyecto Cidadania em Ação, en el área de Educación. El propósito de la investigación de extensión fue seguir, de manera participativa, la oferta deportiva en el grupo de edad de 6 a 14 años. La metodología, de orientación cualitativa, involucró observación participante, entrevistas y cuestionarios. Para el desarrollo del trabajo, se monitorearon tres núcleos donde se desenrollaba el Proyecto, en la ciudad de Río de Janeiro, los cuales atendieron principalmente al grupo de edad objetivo del estudio. Este artículo presenta la evaluación de los participantes sobre el desarrollo de las acciones. El estudio indica aspectos en los que el Proyecto cumple con las propuestas iniciales, en su acción educativa y de integración entre los participantes, así como los límites, señalados por los participantes, en relación principalmente con los materiales puestos a disposición.

Palabras clave: proyecto social; investigación extensionista; satisfacción de los participantes.

\section{INTRODUÇÃO}

[...] educar e educar-se, na prática da liberdade, é tarefa daqueles que sabem que pouco sabem - por isto sabem que sabem algo e podem assim chegar a saber mais - em diálogo com aqueles que, quase sempre, pensam que nada sabem, para que estes, transformando seu pensar que nada sabem em saber que pouco sabem, possam igualmente saber mais. (FREIRE, 1983, p. 15).

Este trabalho apresenta a experiência de três pesquisadores extensionistas, vinculados à área da educação, junto ao projeto Cidadania em Ação, uma iniciativa entre Ministério da Cidadania e Universidade Federal do Estado do Rio de Janeiro (UNIRIO), desenvolvida entre outubro de 2018 e agosto de 2019. Orientase pela concepção de extensão em Freire (1983), lugar em que os saberes são reconhecidos enquanto poucos saberes, tanto dos sujeitos que vão ao campo quanto daqueles que lá estão e, por meio do diálogo, são capazes de se ampliar, gerando saberes capazes de instrumentalizar transformações relevantes para os envolvidos. O objetivo da pesquisa extensionista foi acompanhar, de forma participante, o oferecimento de esporte, por meio do Projeto, para a faixa etária dos 6 aos 14 anos. Este artigo apresenta, a seguir, o Projeto acompanhado, os cuidados indicados por pesquisas na área de projetos sociais para o tratamento do tema e a avaliação dos participantes - professores, supervisores, crianças e 
seus responsáveis - sobre ele. A metodologia, de orientação qualitativa, envolveu observação participante, entrevistas e questionários.

\section{PROJETO ACOMPANHADO}

A UNIRIO submeteu o Projeto Cidadania em Ação ao Ministério do Esporte, ainda em 2018. Em 2019, o Projeto vinculou-se, por meio da Secretaria Especial do Esporte, ao Ministério da Cidadania. O Projeto previu a implementação de Núcleos ${ }^{3}$ voltados ao oferecimento de esportes, recreação e lazer, tendo como objetivo geral:

[...] democratizar o acesso à prática de atividades físicas, esportivas, culturais e de lazer, envolvendo beneficiários a partir de 6 anos de idade, prioritariamente em risco social, inclusive pessoas com deficiência, estimulando a convivência comunitária e a promoção social, através de seus núcleos descentralizados no Estado do Rio de Janeiro. (UNIRIO, 2018, p. 9).

Considerando o objetivo geral, o Projeto se propôs a promover igualdade social, por meio do acesso às atividades de forma gratuita aos participantes; auxiliar no processo educacional, na medida em que a participação em atividades de esporte, lazer e cultura podem contribuir para o desenvolvimento pleno da pessoa, e, ainda, promover a saúde, uma vez que a prática das atividades propostas buscava combater o sedentarismo e promover o desenvolvimento de hábitos saudáveis para o desenvolvimento físico e social.

Os Núcleos seriam formados por um articulador da comunidade, um professor e um monitor (UNIRIO, 2018). As atividades oferecidas foram: alongamento, dança, educação física/recreação, futebol, futsal, ginástica, ginástica para terceira idade,

3 Núcleos: 2 de Fevereiro; Água Santa; Agulhas Negras (Campo Grande); Alto da Boa Vista; Anchieta; Campinho; Capela S. P. Nolasco; Ciep Raul Seixas- Costa Barros; Coelho Neto; Colônia Juliano Moreira; Cond. Jardim do Outeiro; Copacabana; Copacabana (Atlântica); Governador late Clube; Guadalupe; late Clube de Ramos; Jacaré; Jardim América (Ficap); Jardim Guanabara; Manguinhos (Esperança); Muzema; Nova Guaratiba (Campo Grande); Olaria; Olariense; Paquetá; Parque Anchieta; Pavuna (Metrô); Pavuna (Vila Luiza); Piedade; Piscinão de Ramos; Portuguesa (Ilha do Governador); Praça Currupião (Campo Grande); Praça Dom Bosco (Campo Grande); Praça Estrela do Oriente (Campo Grande); Praça João Vita (Campo Grande); Praça Maria Magdala (Campo Grande); Projeto Bela Vista (Bancários); Pro-Morar II; Raízes da Tijuca; Renascer Jacarepaguá; Ricardo de Albuquerque; Rio Comprido (Praça Del Vercchi); Rocinha; Tubiacanga; Vila Vintém; UNIRIO (dois Núcleos: IB e Urca). Nem todos estes Núcleos funcionaram durante os 10 meses de previsão da ação, o compromisso do Projeto era com 45 Núcleos em funcionamento simultâneo. 
ginástica step dance, handebol, hidroginástica, jazz, jiu-jítsu, judô, treinamento funcional, voleibol, zumba. A duração da execução do Projeto foi de 10 meses.

Na UNIRIO, o Projeto vinculou-se à Pró-Reitoria de Extensão e Cultura, que selecionou a empresa Centro de Pesquisas e Ações Sociais e Culturais para atuar na execução do Projeto, com a contratação de professores, supervisores e articuladores comunitários para trabalharem nos Núcleos; compra e fornecimento de material para as atividades; e pagamento de bolsas para pesquisadores extensionistas e estudantes da Universidade. O financiamento do Projeto foi por meio de ementa parlamentar.

Para acompanhar a execução do Projeto, foram selecionados, pela Universidade, por meio do Edital 02/2019, de outubro de 2018, cinco professores do quadro permanente, cada qual com um foco e projeto de trabalho distinto. Estes cinco professores coordenaram pesquisas extensionistas, voltadas ao acompanhamento do Projeto. Em junho de 2018, foram selecionados estudantes para atuarem junto a este acompanhamento. No caso dos professores, o Edital não definia as áreas dos pesquisadores; cada candidato, portanto, apresentou uma proposta de plano de trabalho, além do seu currículo, para avaliação e seleção. Este artigo se dedica a apresentar o trabalho realizado pela área da Educação junto aos Núcleos do Projeto e, mais especificamente, a satisfação dos participantes na realização das atividades.

$\mathrm{Na}$ área da educação, o objetivo do plano de trabalho selecionado foi contribuir com o Projeto Cidadania em Ação, acompanhamento às necessidades de execução, o monitoramento de indicadores, a realização e a análise de relatórios e a execução in loco do Projeto. Partindo deste objetivo geral, foram propostas, de forma vinculada à pesquisa, Gabinete de Pesquisa em Desenvolvimento Curricular, as seguintes ações: acompanhar a inclusão da faixa etária de 6 a 17 anos no Projeto em um dos núcleos; analisar as atividades propostas, em relação às condições de trabalho, às expectativas dos participantes e dos envolvidos na execução e, por fim, contribuir com a coordenação do Projeto, na Universidade, por meio das observações realizadas (FETZNER, 2018). Para a realização do plano de trabalho da educação, foram selecionados para atuarem como bolsistas extensionistas na execução do plano de trabalho, em novembro de 2018, dois estudantes da área, um de pós-graduação, com formação em Educação Física, e outro de graduação, com formação em andamento em Pedagogia. 


\section{A PESQUISA EXTENSIONISTA}

A pesquisa Gabinete de Pesquisa em Desenvolvimento Curricular acompanha escolas em ciclos, que priorizam o agrupamento etário na formação das turmas escolares, buscando identificar orientações e práticas curriculares e avaliativas que contribuam com a integração curricular, entendida tanto como a integração entre os anos escolares, do ponto de vista curricular, quanto com as experiências de vida dos estudantes e as atividades propostas nas escolas. Neste sentido, a pesquisa extensionista aqui apresentada colaborou para a percepção da integração entre as faixas etárias nas atividades esportivas, tal qual o trabalho desenvolvido com as escolas, embora, neste artigo, não seja esta a questão em foco.

O trabalho realizado ocorreu em dois âmbitos: no acompanhamento das necessidades gerais do Projeto, em reuniões periódicas de planejamento, e no acompanhamento in loco de Núcleos que atendiam prioritariamente estudantes entre 6 e 14 anos de idade, oferecendo atividades na área de esporte. A contribuição com a coordenação do Projeto, por meio da participação nas reuniões, junto ao grupo de pesquisadores e Coordenação-Geral, gerou recomendações em relação às observações realizadas in loco, registradas em relatórios mensais, e debate das questões emergentes do desenvolvimento do Projeto, tais como necessidades em relação à organização dos Núcleos na UNIRIO, procedimentos de inscrição nas atividades do Projeto e planejamento do Seminário Cidadania em Ação, oferecido para formação de professores e supervisores.

A pesquisa extensionista é compreendida, pelo grupo envolvido no trabalho aqui apresentado, como aquela que se dá na intersecção entre a pesquisa e a extensão, ambiente de comunicação de saberes, inspirado em Freire (1983), como já apresentado. O trabalho extensionista é colocar em movimento de troca, por meio do diálogo, saberes que buscam complementação recíproca.

A ação extensionista que busca acompanhar um trabalho em realização, no âmbito do Projeto Social proposto pela Universidade, envolve convênios e diretrizes de acompanhamento próprios do serviço público, e, no campo da produção de conhecimento, uma das funções sociais das universidades, a disponibilidade para transformar a experiência em conhecimentos que se submetem à autorreflexão crítica. Este artigo é um dos instrumentos para realização deste 
movimento de autorreflexão de uma experiência que retrata diálogos formativos entre a comunidade que participou da ação e a universidade.

O acompanhamento desenvolvido na área da educação teve, na avaliação da qualidade do projeto, como indicadores, o atendimento das expectativas dos participantes e da estrutura local para desenvolvimento do Projeto. A intencionalidade do plano de trabalho na área da educação era produzir conhecimento sobre este Projeto Social, indicando aspectos relevantes para a sua continuidade e, também, os limites encontrados.

A análise dos dados obtidos com as fichas de inscrição no Projeto possibilitou perceber que os Núcleos dedicados ao atendimento dos mais jovens trabalhavam prioritariamente com crianças na faixa etária dos 6 aos 14 anos, e não até os 17 anos. Este foi o primeiro redirecionamento do foco, tomando o atendimento na faixa dos 6 aos 14 anos como orientação na escolha do Núcleo. Durante a participação no Projeto, foram acompanhados, na cidade do Rio de Janeiro, os Núcleos Raízes da Tijuca, no bairro da Tijuca; Olariense, no bairro Olaria; e Academia Projeção, no bairro Copacabana. O acompanhamento do Projeto em 3 Núcleos, e não apenas um, como inicialmente previsto, decorreu da avaliação da equipe, que, ao visitar o primeiro Núcleo - Raízes da Tijuca, escolhido por atender um grande número de crianças, percebeu a possibilidade da existência de muitas diferenças nas estruturas de trabalho entre os Núcleos, então, no desenvolvimento do trabalho, o acompanhamento foi redirecionado de forma a conhecer outras estruturas, em locais com características diferentes da cidade. Estas diferenças nas estruturas se confirmaram ao final do acompanhamento.

As idas aos Núcleos, no período de desenvolvimento do Projeto, buscaram perceber a organização do trabalho, as condições estruturais do atendimento e conhecer os profissionais. Nos 3 Núcleos acompanhados, a equipe da educação conversou com os supervisores e com os professores contratados para atuação no Projeto. As conversas com as crianças participantes foram registradas apenas no Núcleo da Academia Projeção, onde havia a participação dos responsáveis acompanhando as crianças nas atividades, o que possibilitou a autorização para entrevistas com elas. Todas as participações foram voluntárias. A seguir, serão apresentados os cuidados iniciais ao tratar de projetos sociais na área do esporte e, em seguida, as avaliações decorrentes da pesquisa extensionista realizada. 


\section{PROJETOS SOCIAIS NA ÁREA DO ESPORTE: CUIDADOS INICIAIS}

Uma primeira questão a preocupar os pesquisadores na área da educação foi a discussão, no campo dos estudos, sobre projetos sociais, do conceito de vulnerabilidade. Um dos problemas que cercam a utilização do conceito de vulnerabilidade social é que seu uso pressupõe um apartheid social. No lugar de trabalhar com direitos universais, ou a serem universalizados, o uso do termo vulnerabilidade social estabelece um corte entre aqueles sujeitos que precisariam de uma assistência para que se tornassem cidadãos, com suporte para que pudessem acessar seus direitos, e aqueles que não teriam necessidade deste suporte, porque já se encontram incluídos na cidadania. Carmo e Guizardi (2018, p. 2) destacam:

Situada em um campo de frequentes disputas entre diferentes projetos societários, que revelam concepções distintas de Estado, a seguridade social não contributiva brasileira depara-se com uma correlação de forças que não permite a efetivação de seu princípio de universalidade, fazendo com que acabe por focalizar-se nos sujeitos em situação de vulnerabilidade, além de vivenciar um estado de inconclusão tanto na sua consecução quanto na ideia de cidadania que carrega.

Para os autores, a efetivação do conceito de universalidade de acesso à saúde, educação, previdência e assistência social, associado à Constituição Brasileira de 1988, é o que poderia evitar os problemas que decorrem do uso do conceito de vulnerabilidade, mais exatamente, dos problemas que decorrem da precarização justificada pelo conceito de vulnerabilidade. No Brasil, foi a Constituição de 1988 que, ao romper com a ideia de previdência e assistência apenas para trabalhadores com emprego formal, desenvolveu a ideia de seguridade social não contributiva, ou seja, universalidade da previdência e assistência, mesmo para aqueles que não contribuíram para o fundo econômico que sustenta o sistema de seguridade. Ainda sobre a utilização do conceito de vulnerabilidade, Correia (2008, p. 116) chama atenção:

[...] tem sido recorrente, nos discursos das ações sociais, associar a condição de vulnerável social com a de carente social. Ver esses indivíduos como carentes, permite o surgimento de projetos de educação física, esporte e lazer com um caráter clientelista, assistencialista, paternalista ou utilitarista, oferecendo como benesse aquilo que é um direito. O conceito de vulnerabilidade social está associado aos direitos civis e sociais e às condições de cidadania que, por uma complexidade de fatores, deixam excluídos da condição de cidadãos diversos sujeitos e comunidades. 
Para o autor citado, o conceito de vulnerabilidade social não deve ser associado à carência social, pois essa visão pode promover projetos que colocam a ação social oferecida como um favor, caridade ou ação filantrópica dirigida àqueles que, supostamente, nada teriam (situação de "carente"), e oferecida por aqueles que teriam o poder de manter ou não a ação, dando ou não continuidade ao projeto social. Nesta situação, quando o projeto social não é apresentado e tratado como um instrumento de acesso a direitos constitucionais (saúde, lazer etc.) e uma prestação de serviço neste sentido, os usuários são situados como dependentes das vontades e do poder daqueles que oferecem a ação, provocando uma relação de dependência política. Em sentido contrário ao assistencialismo, a prática do esporte e do lazer precisaria ser percebida como um direito constitucional e não deveria ser oferecida como suplência a uma carência (CORREIA, 2008). O autor também faz um alerta sobre os discursos reducionistas e discriminatórios que utilizam o projeto social para justificar a ocupação do tempo livre das crianças das comunidades tidas como vulneráveis, como se essas, se não estivessem ocupadas em atividades, estariam sendo expostas à criminalidade.

Da mesma forma, Hecktheuer e Silva (2011), ao analisarem 27 projetos mapeados na cidade de Rio Grande, no Rio Grande do Sul, destacaram que os discursos posicionam as pessoas como vulneráveis sociais, transformando-os em público-alvo de políticas sociais do governo. Os projetos e programas funcionam como "tecnologias de governo", como se para governar fosse preciso isolar um grupo e chamá-los de vulneráveis. É como se um projeto social em determinada comunidade legitimasse a vulnerabilidade do público ao qual atende. Os dados obtidos na experiência extensionista reafirmaram a validade destes cuidados iniciais.

\section{OLHAR DOS PROFESSORES E SUPERVISORES SOBRE O PROJETO}

Buscando atender ao objetivo da pesquisa extensionista, de acompanhar de forma participante o oferecimento de esporte na faixa etária dos 6 aos 14 anos, a equipe de pesquisadores extensionistas da área da educação desenvolveu instrumentos de avaliação, aplicados a professores, supervisores, responsáveis e crianças, cada qual com suas especificidades, e instrumentos de registro das visitas aos Núcleos. Dois questionários, um para professores e outro para supervisores do Projeto, foram aplicados em um dos seminários de formação do Projeto, que ocorreu na UNIRIO, em 15 de junho de 2019, como parte do acompanhamento 
de professores e supervisores. Destaca-se que a avaliação desenvolvida no acompanhamento do Projeto, de forma dialógica e continuada, foi utilizada durante o processo, buscando suas contribuições para a qualificação contínua, e não em uma perspectiva classificatória, ao final do processo.

Os questionários foram respondidos de forma anônima, apresentaram poucas questões e focaram-se na expressão da satisfação (e insatisfação, por consequência) dos respondentes. As perguntas aos professores envolviam um quadro com oito critérios de satisfação: desempenho de seu trabalho na função de professor no Projeto; trabalho na instituição onde o Projeto era desenvolvido; trabalho com a empresa contratante; vínculos desenvolvidos com os participantes, nas aulas; condições estruturais do local onde as atividades são oferecidas (espaço físico, ventilação, refrigeração, relação espaço e número de pessoas atendidas); quantidade de material oferecido para desenvolvimento do Projeto; número de pessoas atendidas nas aulas; desenvolvimento das pessoas atendidas pelo Projeto (a partir das atividades propostas nas aulas). Para cada um dos itens, os professores atribuíam um grau de 1 até 5 , sendo 1 para nada satisfeito e 5 para totalmente satisfeito. Após este quadro, os professores encontravam um espaço para explicar alguma questão relativa às respostas anteriores, já que o quadro permitia apenas a atribuição do grau. Em questões posteriores, o questionário também levantava o tempo de trabalho no Projeto e o quanto a remuneração recebida para este fim seria responsável pelo rendimento mensal do professor, em percentuais que iriam de $10 \%$ a mais de $50 \%$ do seu rendimento mensal. Ao final, com questões abertas, o questionário apresentava um espaço para que o professor, se desejasse, indicasse um aspecto positivo do Projeto e outro espaço para que indicasse, também optativamente, um aspecto em que esse poderia melhorar.

Os questionários foram aplicados a 26 professores e possibilitaram observar que oito deles tinham menos de 6 meses de atuação no projeto, e os demais, mais de 6 meses. Quanto à participação da remuneração do trabalho no Projeto na composição de sua renda individual mensal, 13 professores declararam que a remuneração pela participação representava entre 30\% e 50\%, oito professores indicaram que representaria mais de $50 \%$ e cinco indicaram que representaria menos de $10 \%$. Isto nos possibilita perceber a dependência, na renda individual dos professores contratados, em relação ao Projeto. 
Gráfico 1 - Professores: avaliação dos critérios de satisfação em relação ao Projeto

\section{Satisfação dos Professores}

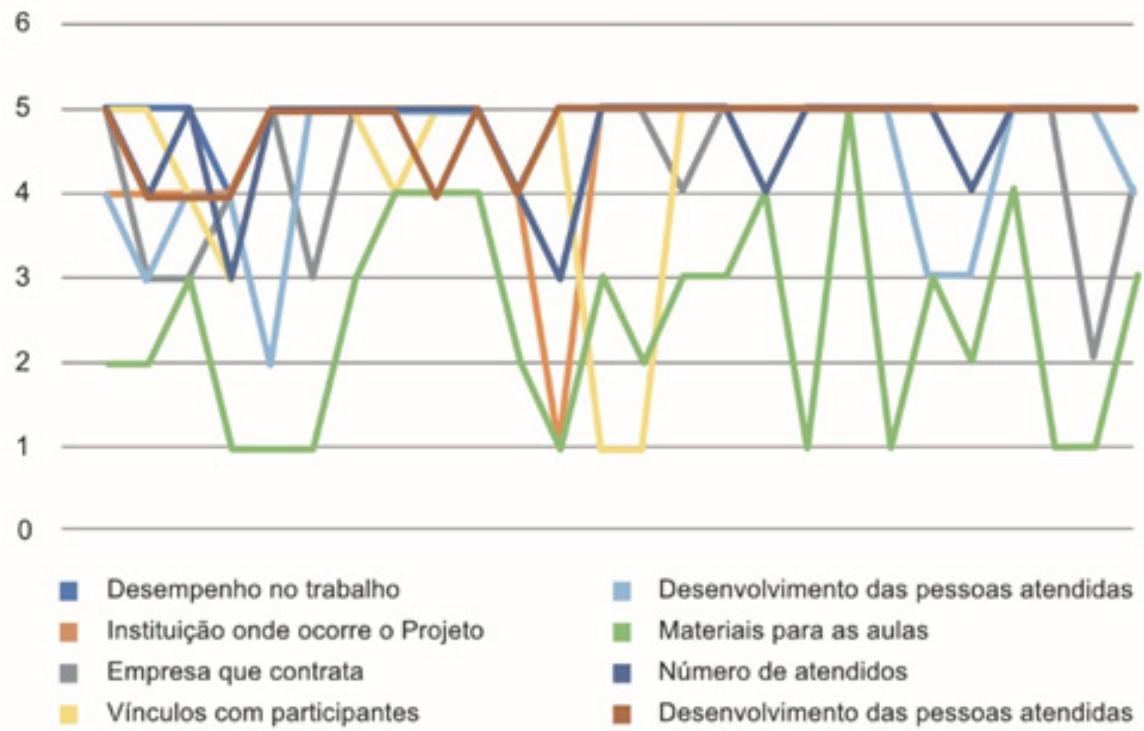

Fonte: Dados da pesquisa.

O Gráfico 1, com o resultado dos 26 questionários respondidos pelos professores sobre a satisfação com cada critério (descritos na legenda), demonstra que o item de maior satisfação foi em relação ao próprio desempenho no projeto, apenas quatro professores não se encontravam totalmente satisfeitos com o próprio trabalho. Se considerarmos 4 e 5 como avaliações positivas sobre o local onde o Projeto funcionava, encontramos apenas um professor razoavelmente satisfeito e um professor nada satisfeito. Nenhum destes dois professores utilizaram o espaço disponível para explicação de suas respostas quanto ao grau de satisfação dos critérios solicitados, todavia os dois respondentes citaram, posteriormente, em questões abertas, a falta de material para execução das aulas como um ponto a melhorar, o que pode representar um dos problemas que afetaram o grau de satisfação em relação ao local onde o trabalho se desenvolvia.

No que se refere à empresa contratante, um professor não respondeu, três se encontravam razoavelmente satisfeitos e um professor atribui grau 2, ou seja, 
não estava satisfeito. Nenhum destes três professores comentaram sobre esta questão no espaço destinado a isto. Em relação aos vínculos com os participantes, os questionários revelam um professor razoavelmente satisfeito (atribuição de grau 3) e dois nada satisfeitos (atribuição de grau 1). O professor que atribuiu o grau 3 e um dos professores que atribuiu grau 1 não explicaram suas insatisfações, já o segundo professor que atribuiu grau 1 escreveu, na questão destinada a comentários sobre as respostas a este quadro, que o grau 1 atribuído referia-se a sua insatisfação com a equipe de trabalho, sem detalhamento sobre isto.

No que se refere às condições estruturais do local onde se desenvolvia o Projeto, três professores se declararam razoavelmente satisfeitos (atribuição de grau 3). Entre as questões citadas ao comentar os graus atribuídos, estavam a necessidade de presença de equipe multidisciplinar e o espaço físico inadequado. Houve um insatisfeito (atribuindo grau 2), sem apresentar alguma declaração específica do motivo. Ao ser avaliada a satisfação com o material recebido, encontramos a insatisfação mais significativa, apenas seis dos 26 professores indicaram satisfação (um atribuindo grau 5 e cinco professores atribuindo grau 4). Entre os demais, sete professores atribuíram grau 3 neste quesito, cinco atribuíram grau 2 e oito atribuíram grau 1. Dezoito questionários citaram, nos espaços de questões abertas, a necessidade de mais material para desenvolvimento das aulas, o que demonstra aqui um aspecto importante a ser observado na futura execução de projetos sociais: a distribuição, que, segundo os dados levantados, não foi satisfatória. Para próximos acompanhamentos, seria importante analisar como é realizado o cálculo da necessidade, as compras e a distribuição dos materiais.

Por fim, ao avaliarem o número de atendidos pelo Projeto, apenas dois professores consideraram razoável sua satisfação, e, quanto às questões abertas destes dois questionários, as observações referiram-se somente à falta de material. No que se refere ao desenvolvimento dos participantes, os professores o avaliaram como satisfatório; cinco professores atribuíram grau 4 a este quesito, e 21 professores, grau 5.

Nas perguntas abertas, no que se refere aos aspectos em que o projeto poderia melhorar, destaca-se novamente que 18 professores, entre os 26 , citaram a necessidade de atendimento quanto aos materiais a serem utilizados nas aulas; dois citaram a necessidade de psicólogo ou equipe multidisciplinar para atendimento aos alunos e dois se referiram a um espaço físico melhor; destes, 
um citou a necessidade de espaço para eventos externos. Um professor sugeriu mais divulgação e outro a renovação contínua, evitando a interrupção, e, ainda, um professor citou as dificuldades com sua equipe de trabalho.

Sobre os aspectos destacados como positivos, também em questões abertas, cinco professores citaram questões ligadas à melhoria da qualidade de vida dos estudantes, incluindo detalhamentos, em diferentes respostas, quanto aos aspectos físicos, mentais e afetivos, socialização e promoção da saúde; quatro professores citaram a inclusão social, contendo, em duas destas respostas, a questão de atendimento aos carentes ou mais necessitados (expressões utilizadas pelos professores). Ainda, foram citados como aspectos positivos do Projeto: aceitação da comunidade; atendimento ao Art. 60 da Constituição Federal, no que se refere ao direito à saúde, à educação e ao lazer; transformação social; relacionamento com a equipe de trabalho e com os alunos; trabalho com a equipe da UNIRIO; pagamento em dia e respeito à equipe de trabalho, por parte dos contratantes. Estes quesitos foram citados uma vez, por professores diferentes.

O questionário aplicado aos supervisores apresentava perguntas sobre a satisfação destes com o desempenho no trabalho, com a comunidade onde o trabalho era oferecido, com a empresa contratante, com os vínculos com os participantes, com as condições estruturais e material, o número de atendidos pelo projeto e o desenvolvimento pessoal das pessoas atendidas. Cada supervisor, na organização do Projeto, acompanharia cerca de 11 Núcleos, conforme regiões da cidade do Rio de Janeiro. Tivemos três supervisores que responderam voluntariamente ao questionário, participantes da mesma formação que os professores, em 15 de junho de 2019.

Quanto ao tempo de participação no Projeto, os supervisores 1 e 3 são os que possuem entre 6 e 12 meses de participação e o supervisor 2, o mais satisfeito, o menor tempo, entre 1 e 6 meses. O questionário também solicitava a manifestação quanto à participação na renda individual dos valores recebidos por meio do Projeto: o supervisor 1 atribuiu entre 10\% e 30\% do seu rendimento mensal; o supervisor 2, entre $30 \%$ e $50 \%$; e o supervisor 3 , mais de $50 \%$. Nas questões abertas, os supervisores citaram os aspectos sociais envolvidos, a socialização e o apoio aos jovens e às crianças como dados positivos do Projeto. E, entre os aspectos que poderiam melhorar, a frequência maior dos coordenadores e a violência nas proximidades dos Núcleos. 
Gráfico 2 - Supervisores: avaliação dos critérios de satisfação em relação ao Projeto

\section{Satisfação dos Supervisores}

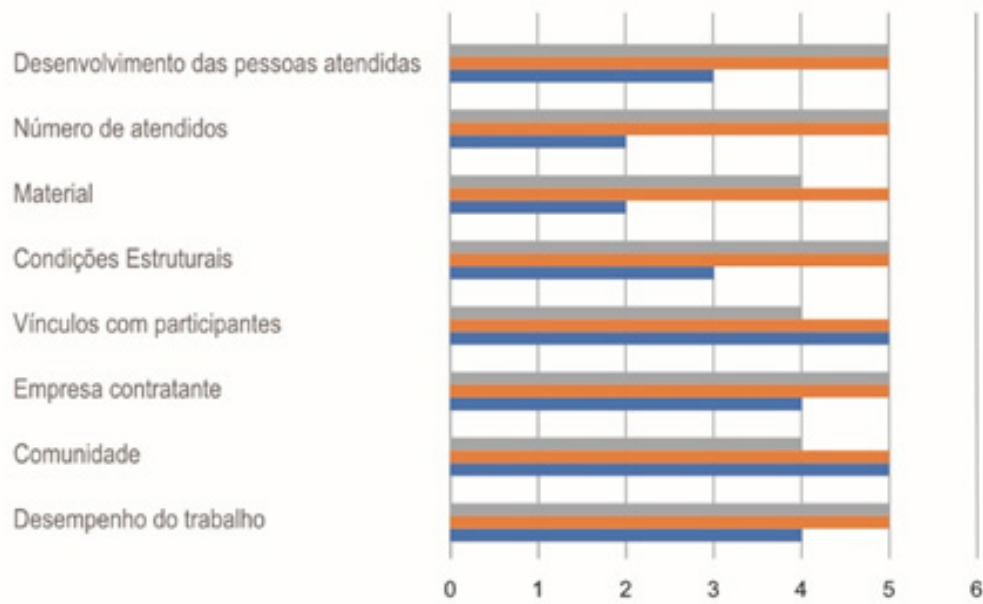

$\left({ }^{*}\right)$ A série 1 representa as respostas do supervisor 1; a série 2, supervisor 2; série 3, supervisor 3. Fonte: Dados da pesquisa.

A análise do gráfico mostra que um dos supervisores, representado pela série 2, está plenamente satisfeito com todos os itens propostos para avaliação, já o supervisor 1 atribuiu insatisfação com o material oferecido para desenvolvimento do trabalho (grau 2) e razoavelmente satisfeito (grau 3) com as condições estruturais dos locais em que o Projeto acontece e com o número de pessoas atendidas pelo Projeto. O supervisor representado na série 3 destacou razoável satisfação apenas em relação às condições estruturais, os locais onde o Projeto acontece.

Analisando os questionários dos supervisores, é possível verificar que os aspectos estruturais, incluindo também a questão da violência nas proximidades dos Núcleos, citadas nas questões abertas, parecem ser as questões mais desafiadoras para a melhoria do Projeto.

\section{OLHAR DOS RESPONSÁVEIS E DAS CRIANÇAS SOBRE O PROJETO}

No desenvolvimento da pesquisa, foram ouvidas nove crianças e os nove responsáveis por cada uma delas, aplicando entrevistas para avaliação da qualidade do Projeto. O roteiro das entrevistas abordavam sobre o ano de nascimento 
da criança que frequentava o Projeto, a escola, o horário de estudos na escola, o horário de participação no Projeto, o bairro de moradia, motivo da participação da criança no Projeto, quem escolheu que a criança participasse, como a família soube da existência do Projeto, o que considerava positivo na participação, o que melhoraria no Projeto, a participação anterior da criança em outro Projeto na área do esporte e quando a criança iniciou-se no Projeto.

Foram entrevistados responsáveis por crianças que nasceram entre 2006 e 2012, portanto, que tinham, em 2019, entre 7 e 13 anos; cinco crianças estudavam em escolas municipais, uma em um centro educacional com objetivos filantrópicos, e duas em escolas adventistas. Apenas uma criança estudava parcialmente em algumas manhãs, além de todas as tardes; as demais, em apenas um turno (manhã ou tarde). Os horários de participação no Projeto variam entre manhã e tarde, e a Academia Projeção, espaço onde as crianças e os responsáveis foram entrevistados, oferece as atividades de jiu-jítsu nos turnos da manhã e da tarde, entre duas e três vezes na semana. Foi informado pelo proprietário, em conversa com os pesquisadores extensionistas, que as crianças poderiam participar no horário em que pudessem, não sendo fixo o horário para cada um. Todas as crianças moram no bairro da Academia, em Copacabana, e os motivos da participação mais citados foram o gosto das crianças pelo esporte (quatro citações), a necessidade de lazer e socialização (três citações), necessidades relacionadas à saúde (duas citações) e à disciplina (uma citação). No que se refere a quem foi o responsável pela escolha da participação da criança nesta atividade, cinco responsáveis citaram os familiares (avós, pais, parentes próximos) e três a criança. Como aspectos positivos na participação das crianças no Projeto, os responsáveis indicaram: aspectos ligados à disciplina - responsabilidade, desenvolvimento cognitivo, concentração e desenvolvimento físico (seis responsáveis); socialização (um responsável); saúde (um responsável); e a felicidade da criança (um responsável).

Tomando-se as informações das famílias, é possível perceber como o conceito de carente ou vulnerável não é aplicável para descrever a demanda de atividades esportivas pelas famílias. O fato de famílias procurarem serviços gratuitos para que as crianças pratiquem esporte, socializem-se, possam melhorar a saúde e a disciplina não os coloca em lugar de destacada vulnerabilidade social, conforme apregoam os projetos. 
Como indicação de melhoria ao Projeto, 3 responsáveis pelas crianças citaram, respectivamente, a necessidade de aumentar o número de turmas e ampliar os horários, o espaço maior e a possibilidade de financiar o exame de troca de faixa, a participação em competições e o quimono (que são práticas pagas, o que inviabiliza a participação de muitos). Apenas duas crianças não participavam, anteriormente, de outro projeto social na área do esporte. Três responsáveis indicaram a participação das crianças em período anterior ao início do Projeto (dois em agosto de 2018 e um em setembro de 2018, enquanto o Projeto iniciou-se em outubro de 2018), o que pode ser decorrente de equívoco dos respondentes ou de que a Academia em questão participava, anteriormente, de outro projeto social. Cinco crianças começaram em 2019 e uma em dezembro de 2018.

As entrevistas com as crianças foram acompanhadas de um instrumento de registro para algumas perguntas. Estes instrumentos ofereciam, como respostas às questões, o desenho de três carinhas, as quais simbolizavam satisfação (carinha sorrindo), indiferença (carinha sem expressão de sorriso ou tristeza) e descontentamento (carinha triste). As questões tratavam da frequência ao Projeto (se gostavam, eram indiferentes ou não gostavam); o horário das atividades; o local das atividades; os materiais disponíveis para realização das atividades; os colegas de atividade; o professor; as atividades. Após a avaliação das crianças sobre estes aspectos do Projeto, era possível que a criança falasse mais sobre algum dos itens avaliados, de acordo com seu interesse em fazê-lo. Também Ihes era perguntado sobre quem escolheu participar do Projeto, se elas ou os responsáveis. Por fim, as crianças eram questionadas sobre o que gostavam no Projeto e o que poderia melhorar.

Entre as nove crianças ouvidas, apenas duas apontaram aspectos com os quais não estariam satisfeitas com o projeto. Uma das crianças disse estar indiferente (não achou bom ou ruim) com os colegas e outra criança se disse indiferente aos horários e local da atividade oferecida. Uma das crianças que respondeu positivamente a tudo destacou que gostava do professor porque ele brincava bastante e não era bravo. Três crianças disseram ter escolhido participar do Projeto e as 6 outras atribuíram a escolha a seus responsáveis ou familiares, o que corresponde às respostas obtidas junto aos responsáveis.

Ao citar o que gostavam no Projeto, as crianças se referiram às lutas, quedas, brincadeiras, atividades, tatame (seis crianças); aos campeonatos e trocas de 
faixa (uma criança); aos professores (duas crianças); aos amigos (uma criança). Sobre o que poderia melhorar no Projeto, cinco crianças disseram que o espaço, o tatame e a sala de materiais poderiam ser maiores.

O conjunto das respostas possibilita perceber que o Projeto foi bem recebido pelos envolvidos e atendeu às expectativas de promoção do esporte e de inclusão social. No que se refere aos problemas percebidos pelos participantes, o foco das observações foi em relação ao fornecimento de materiais para as aulas e, também, em algumas observações, a necessidade de oferecimento em locais mais apropriados, ao menos ao considerar o que disseram os usuários no Núcleo pesquisado, ao indicarem mais espaço e estrutura.

No que se refere aos trabalhadores (professores e supervisores contratados pelo Projeto), foi possível observar também que a participação no Projeto implica parte importante da remuneração mensal. Ou seja, o Projeto não atende às necessidades apenas das crianças e de suas famílias, na promoção do esporte como direito a um desenvolvimento integral, mas também na promoção de renda aos professores e supervisores contratados. A seguir, buscando concluir a análise sobre a experiência descrita, serão retomadas as reflexões que orientaram a pesquisa em relação aos cuidados no trabalho com projetos sociais e que muito colaboraram para o olhar avaliativo que permeou este trabalho, desenvolvido no campo da educação.

\section{CONCLUSÕES}

Este artigo apresentou o acompanhamento desenvolvido pela área de educação junto ao Projeto Cidadania em Ação, realizado pela UNIRIO, em conjunto com o Ministério da Cidadania, por meio da Secretaria Especial do Esporte. Ao todo, o Projeto atendeu a 4.538 beneficiários, em 45 Núcleos que mantiveram funcionamento simultâneo durante o Projeto (FETZNER; CARVALHO JR.; SANTOS, 2019). A área de educação teve por objetivo contribuir com o Projeto no acompanhamento das necessidades de implementação, junto à coordenação geral na Universidade, e analisar o trabalho quanto às condições de realização desse e ao atendimento das expectativas dos participantes. Para isto, além da participação nas reuniões gerais com a coordenação, a área propôs acompanhar um destes Núcleos, no qual houvesse a predominância da faixa etária dos 6 aos 17 anos. 
Iniciados os trabalhos, verificou-se que os Núcleos que atendiam crianças tinham como predominância a faixa etária de 6 a 14 anos e que as condições estruturais de funcionamento eram muito diferentes. Buscando conhecer estas diferenças, e atendendo a especificidade etária do Núcleo, o acompanhamento envolveu visitas em 3 Núcleos (Raízes da Tijuca, Olariense e Copacabana Academia Projeção), participação em um Seminário de Formação de professores e supervisores, em junho de 2019, aplicação de questionários a professores e supervisores; entrevistas com responsáveis por crianças e crianças participantes (Núcleo Copacabana).

Uma das preocupações no campo dos estudos sobre projetos sociais na área do esporte é com a caracterização da população a ser atendida como carente ou vulnerável, de forma a ocultar as condições objetivas que produzem a existência de grande parte da população brasileira que não tem assegurados seus direitos fundamentais de acesso à saúde, à educação, ao lazer, ao desenvolvimento esportivo e demais aspectos que compõem a cidadania. Esta população, quando colocada na condição de vulnerável, pelos que ofertam os projetos sociais, tem reforçada sua condição de que, àquele que nada tem, qualquer coisa pode ser oferecida.

Por meio do acompanhamento do Projeto, que tomou a centralidade do trabalho aqui apresentado, foi possível perceber que os responsáveis pelas crianças e as crianças ouvidas nesta pesquisa identificam como questões a meIhorar no Projeto: a necessidade de aumentar o número de turmas e ampliar os horários, a necessidade de espaço maior e de financiamento para participação em competições de troca de faixas (pagas, no caso do jiu-jítsu) e quimonos. Assim como foi indicado pelos responsáveis, as crianças também avaliaram que o espaço, o tatame e a sala de materiais poderiam ser maiores, ou seja, o fato de o Projeto ser oferecido sem que a participação seja paga diretamente pelos participantes não implicou, ao menos entre estes participantes, julgar que qualquer coisa a ser oferecida seria satisfatória. Este mesmo grupo, formado pelas crianças e seus responsáveis, também indicou como positivo o Projeto, para o desenvolvimento dos envolvidos. Os responsáveis apontaram, com destaque positivo, questões relacionadas à disciplina, e as crianças, por sua vez, à importância de poderem participar das lutas, das quedas, das brincadeiras e das atividades de forma geral. 
Também, entre professores e supervisores, os benefícios do Projeto foram reconhecidos, com destaque para o desenvolvimento das pessoas que dele participam, desempenho no trabalho, instituição onde o trabalho acontece e relação com a empresa contratante. Como questão a ser melhorada no Projeto, foi notória a indicação da necessidade de mais materiais para as aulas, e algumas observações quanto à estrutura de funcionamento no Projeto. O acompanhamento presencial aos Núcleos também identificou dificuldades estruturais, como a falta de vestiários, bebedouros (nos 3 Núcleos) e refrigeração (1 Núcleo), entre outras carências estruturais, encaminhadas à coordenação.

Nas falas dos professores e supervisores, foi possível identificar dois aspectos apontados pelos estudos no campo como cuidados a serem tomados no tratamento destes projetos: tanto a visão sobre os usuários como carentes quanto a ideia de que a atividade esportiva oferecida seria uma espécie de proteção em relação às crianças, uma vez que, se não estivessem no projeto, poderiam ser cooptadas pelo crime. Percebeu-se que estas questões precisam ainda serem trabalhadas com os professores e supervisores, assim como questões tratadas na oficina oferecida no seminário de formação, ocorrido em junho de 2019, que se referem à forma de combater a exclusão social (quer seja por gênero, quer seja por raça ou por deficiência física) junto às turmas atendidas.

A oficina oferecida pela área da educação teve como enfoque a inclusão de estudantes com deficiência nas turmas do Projeto e propôs um debate na temática desde a vivência de atividades práticas e de debate, em que os professores e supervisores conversavam sobre como era feita a inclusão nas turmas. Os desafios quanto a trabalhar com questões de gênero e raça também apareceram, sendo colocados pelos professores. A maioria dos participantes se pronunciou, na avaliação da atividade, reivindicando mais formação e a importância do tema para suas práticas docentes.

No que se refere à caracterização da população atendida pelo Projeto, é possível destacar que, no lugar de carentes ou vulneráveis, encontram-se pessoas que organizam sua vida por meio do trabalho, cujos filhos estudam, nem todos em escolas públicas. Essas famílias não possuem renda suficiente para pagamento de academias e, diante de uma educação escolar que ainda não é em tempo integral, precisam recorrer à complementação de atividades esportivas via projetos sociais. Se há uma carência, ela se refere aos serviços públicos prestados, desde a escola pública, e à remuneração do trabalho dos responsáveis. 
Destaca-se que, no Brasil, em 2017, os 10\% mais pobres detêm apenas $0,8 \%$ da renda nacional, enquanto os $10 \%$ mais ricos possuem $43,3 \%$ da renda; a renda média da metade mais pobre da população brasileira era de $\mathrm{R} \$ 754,00$ por mês; a renda média da população brasileira, no mesmo ano, era de $\mathrm{R} \$ 2.112,00$. Isto significa que, se a sociedade fosse menos desigual, esta seria a renda percebida pela maioria (UOL ECONOMIA, 2018), ou seja, estas famílias, atendidas pelo Projeto, não se encontram distantes da situação da maioria da população brasileira e, assim, atender às suas necessidades não implica atender à carência ou vulnerabilidade social, mas atender à demanda, que é também um direito Constitucional, de grande parte da população brasileira: o acesso à prática de esporte. O Projeto atende a uma necessidade da população brasileira, de forma paliativa, enquanto as escolas não se tornarem de tempo integral e não assumirem a formação em esportes como parte do desenvolvimento humano e direito de todos, percebido em seu caráter de universalidade e não associado ao conceito de vulnerabilidade. Aqui, encontra-se aspecto importante para a pesquisa Gabinete em Desenvolvimento Curricular: a necessidade de uma escola democrática, integral, com oferta de artes e educação física sem favorecimento das demais áreas de conhecimento.

Considera-se, portanto, como importante no desenvolvimento de projetos na área do esporte, que o caráter do projeto não reforce a ideia de que quem dele precisa seria vulnerável ou carente, uma vez que a necessidade do projeto é atender parte dos direitos básicos da população, em uma sociedade extremamente desigual. O caráter transitório dos projetos também é problemático, pois o direito ao acesso à prestação de serviços ligados ao desenvolvimento do esporte, do lazer e da cultura se torna intermitente. Parte do problema decorre de o Projeto ter utilizado verbas de ementa parlamentar, o que precisa de mais estudo nas suas contradições. As ementas parlamentares têm sido instrumento de aplicação do orçamento público junto à base eleitoral dos parlamentares e, ainda, como problema, geram projetos intermitentes. A verba de execução termina, mas a demanda da população pelo serviço prestado, não.

No caso da faixa etária foco deste trabalho, 6 a 14 anos, as escolas seriam uma possibilidade deste atendimento, desde que o tempo de permanência na escola fosse ampliado, assim como os recursos voltados ao oferecimento destas atividades e a incorporação de espaços esportivos adequados. 
Destaca-se, ainda, pela vivência que a área de educação teve durante o Projeto e mediante a continuidade de projetos desta natureza, a relevância deles para a população atendida; a necessidade de formação continuada para os que trabalham com estes projetos, demandada pelos professores ouvidos, e do relativo grau de criticidade e independência da população usuária para avaliação dessas ações; e, como preconiza Freire (1983), a importância do diálogo entre os responsáveis pela execução do projeto com os que dele fazem uso, para a melhoria do trabalho desenvolvido, tanto quanto para sua constante qualificação.

\section{REFERÊNCIAS}

CARMO, Michelly Eustáquia; GUIZARDI, Francini Lube. O conceito de vulnerabilidade e seus sentidos para as políticas públicas de saúde e assistência social. Cadernos de Saúde Pública, Rio de Janeiro, v. 34, n. 3, e00101417, 2018. p. 1-14. Disponível em: http://www. scielo.br/scielo.php?script=sci_arttext\&pid=S0102-311X2018000303001\&lng=pt\&nrm= iso. Acesso em: 10 mar. 2020.

CORREIA, Marcos M. Projetos sociais em educação física, esporte e lazer: reflexões e considerações para uma gestão socialmente comprometida. Revista Eletrônica da Escola de Educação Física e Desportos - UFRJ, Rio de Janeiro, v. 4, n. 1, jan./jun. 2008, p. 114-27.

FETZNER, Andréa R.; CARVALHO JR., Arlindo Fernando P.; SANTOS, Laís C. Relatório final de cumprimento de objeto - Projeto Cidadania em Ação/Área da Educação. Rio de Janeiro: UNIRIO, 2019. 8 p.

FETZNER, Andréa R. Proposta de Trabalho Área da Educação ao Projeto Cidadania em Ação. Apresentada ao Edital n. 09/2018 - Processo de seleção de bolsistas extensionistas para atuarem no Projeto Cidadania em Ação. Np. 2018. 3 p.

FREIRE, Paulo. Extensão ou comunicação? Tradução de Rosisca Darcy de Oliveira. 7. ed. Rio de Janeiro: Paz e Terra, 1983.

HECKTHEUER, Luiz Felipe A.; SILVA, Méri Rosane S. Projetos Sociais Esportivos: Vulnerabilização e Governo. Movimento, Rio Grande do Sul, v. 17, n. 3, p. 115-32, 2011.

UNIVERSIDADE FEDERAL DO ESTADO DO RIO DE JANEIRO [UNIRIO]. Pró-Reitoria de Extensão. Proposta de Trabalho Projeto Cidadania em Ação. Anexo IV. Np. Rio de Janeiro: UNIRIO, 2018. UOL ECONOMIA. Renda do $1 \%$ mais rico é 34 vezes maior que da metade mais pobre, diz IBGE. Portal de notícias UOL, 2108. Abr. 2018. Disponível em https://economia.uol.com. br/noticias/redacao/2018/04/11/concentracao-renda-ibge.httm Acesso em: 2 nov. 2019. 


\section{Sobre os autores:}

Andréa Rosana Fetzner: Pós-Doutora pela Universidade Federal do Rio de Janeiro (UFRJ). Doutora em Educação pela Universidade Federal do Rio Grande do Sul (UFRGS). Mestre em Educação pela Universidade do Vale do Rio dos Sinos (UNISINOS). Licenciada em Ciências Sociais pela UNISINOS. Professora do Departamento de Didática e do Programa de Pós-Graduação em Educação e do Programa de Pós-Graduação em Música na Universidade Federal do Estado do Rio de Janeiro (UNIRIO). E-mail: akrug@uol.com.br, Orcid: http://orcid.org/0000-0002-0034-4095

Arlindo Fernando Paiva de Carvalho Junior: Doutorando em Educação pela Universidade Federal do Estado do Rio de Janeiro (UNIRIO). Mestre em Ciências da Atividade Física pela Universidade Salgado de Oliveira (UNIVERSO). Especialista em Docência no Ensino Superior pela Universidade Cândido Mendes (UCAM); em Docência no Ensino Básico com ênfase em Educação Física Escolar pelo Colégio Pedro II (CPII); em Planejamento, Implementação e Gestão da Educação a Distância e em Educação Física Escolar pela Universidade Federal Fluminense (UFF); em Educação Tecnológica pelo Centro Federal de Educação Tecnológica Celso Suckow da Fonseca (CEFET/RJ); e em Esportes e Atividades Físicas Inclusivas para Pessoas com Deficiência pela Universidade Federal de Juiz de Fora (UFJF). Formado em Licenciatura Plena em Educação Física pelo Centro Universitário Augusto Motta (UNISUAM). Professor pesquisador estatutário do Instituto Benjamin Constant. E-mail: afjr18@hotmail.com, Orcid: https://orcid.org/0000-0002-5041-8232

Laís Conceição dos Santos: Graduanda em Pedagogia na Universidade Federal do Estado do Rio de Janeiro (UNIRIO). Professora da Educação Básica. E-mail: laissantospedagogia@edu.unirio.br, Orcid: https://orcid.org/0000-0002-4160-552X

\section{Recebido em: 22/02/2021 \\ Aprovado em: 13/05/2021}


